\title{
Intergenerational Transmission of Trajectories of Offending over Three Generations
}

\author{
Sytske Besemer $^{1}$ • Johan Axelsson ${ }^{2}$ • Jerzy Sarnecki ${ }^{2}$
}

Received: 23 December 2015 /Revised: 27 April 2016 / Accepted: 6 July 2016 /

Published online: 3 September 2016

(C) Springer International Publishing AG 2016

\begin{abstract}
Purpose Crime runs in families: a convicted parent is a risk factor for children's criminality. What is the extent of intergenerational transmission in Sweden? Is transmission similar for men and women and/or do we see gender-specific transmission? To what extent do children follow similar offending trajectories as their parents? Methods We used group-based trajectory modelling to study intergenerational transmission in the Stockholm Life Course Project. By merging the samples when running the trajectory models, we get a more robust model than if we had run the samples separately.

Results Children of convicted parents are about 2-2.6 times more likely to have a conviction compared with children of non-convicted parents. We did not find strong support that intergenerational transmission is stronger for same-gender relationships. Transmission seems slightly stronger to daughters and from mothers, but few of these patterns are significant. Although father and offspring trajectories look similar, the significant relationship can be explained by the observation that non-offending fathers are more likely to have non-offending sons. Fathers with more chronic offending trajectories do not necessarily predict sons with similar more chronic offending trajectories.

Conclusions We find strong intergenerational transmission of criminal behaviour, but offspring convictions are related to the fact that fathers have a conviction rather than to what their conviction trajectory looks like.
\end{abstract}

Keywords Intergenerational transmission · Trajectories · Offending · Sweden

Sytske Besemer

besemer@berkeley.edu

1 Institute of Human Development, University of California, Berkeley, 1205 Tolman Hall, Berkeley, CA 94720, USA

2 Department of Criminology, Stockholm University, Universitetsvägen 10C 106 92, Stockholm, Sweden 


\section{Introduction}

Importance of the family for the development of criminal and other problem behaviours among young people has been recognized in Sweden in the 1960s through the empirical study of child psychiatrist Gustav Jonsson [48, 49]. Jonson was the director of the children's village of Skå-Edeby (since 1947), which carried out the treatment of children and teenagers with serious social problems, among which crime was very common. In his empirical research on 100 boys and their families treated at Skå plus a representative sample of 222 Stockholm boys, he observed that social problems were transferred through 'social heritage' from grandparents and parents to the children. Jonsson's Theory of Social Heritage ${ }^{1}$ had great influence in Sweden and contributed to the development of family-oriented treatment for young offenders.

Despite the long tradition of discussing crime in terms of intergenerational transmission in Sweden, there are few studies investigating this topic. Using the Stockholm Birth Cohort Study, a sample of 15,117 individuals (7719 men and 7398 women), Hjalmarsson and Lindquist [39] demonstrated that children of criminal fathers have between 2 to 2.6 times higher odds of having a criminal conviction than those with non-criminal fathers. Murray et al. [58] used the same sample to investigate intergenerational transmission as well as the impact of parental incarceration and reached a similar conclusion. Kendler et al. [50] investigated intergenerational transmission in a large sample $(N=3,257,987)$ of all people born in Sweden between 1960 and 1990. Again, offspring (who grow up with their biological parents) are twice as likely to become criminal if their parents committed crime compared with offspring without criminal parents.

Internationally, there are a number of studies showing that crime runs in families $[6,20,32,79-82,86]$. Criminal parents are one of the strongest factors predicting offspring offending [20]. Farrington [20] has described six explanations for the intergenerational transmission of criminal behaviour: intergenerational exposure to multiple risk factors, mediation through environmental risk factors, teaching and cooffending, genetic mechanisms, assortative mating and official (police and justice) bias. These explanations are not mutually exclusive, and they are empirically intertwined; a combination of these mechanisms could explain intergenerational transmission.

In this paper, we explore intergenerational transmission of crime in Sweden by employing group-based trajectory modelling [61]. Using data from the Stockholm Life Course Project (The 100 Skå boys Jonsson investigated are included as a part of the data in this study), we investigate the following questions:

1. What is the extent of intergenerational transmission in the Stockholm Life Course Project?

2. Is intergenerational transmission similar for men and women and/or do we see gender-specific transmission?

3. To what extent do children follow similar offending trajectories as their parents?

\footnotetext{
${ }^{1}$ Jonsson was strongly convinced that social problems are inherited through social processes, mainly within the family. Today, there is extensive research showing that transmission of crime and other social problems between the generations is a process where biological and social factors interact with each other in a sophisticated way (e.g. [17]).
} 
Investigating intergenerational transmission in different countries is relevant to explore the impact of national crime policies. As Farrington and Loeber ([23], p. 300) stated, 'Cross-national comparisons of risk factors for delinquency are important for addressing the question of how far the causes of delinquency are similar in different times and places'. Sweden is particularly interesting, because Scandinavian countries are generally viewed as having mild and benign criminal justice policies with humane prison conditions. The Swedish welfare state has a long tradition of using different types of measures to seek to equalize the social gaps [67]. There are several reasons why having a convicted parent might impact children less in Sweden compared with other countries. First, the Swedish juvenile justice system might prevent intergenerational transmission, as child welfare, and not punishment, was the focus in youth offending $[44,58]$. Second, the egalitarian welfare state might have provided children of convicted parents with enough resources to mitigate and overcome the impact of parental crime, because 'the basic needs of all Swedish citizens for a minimum income, job security, satisfactory health care, educational opportunities, adequate housing, good public transportation, and other social services have been met' ([88], p. 152). Third, public opinion on crime and punishment in Sweden might reduce the impact of parental conviction for children. An example of the strong influence of penal and political environment on reactions to crime and stigma is described by Green [34, 35] who studied this in relation to the subject of child-on-child homicide. He compared the English and Norwegian criminal justice systems and the public response to the cases of James Bulger and Silje Redergard. In Norway, the young killers were shielded from the public and carefully reintegrated into the community because it was believed that this was a tragic one-off accident, while in England, James Bulger's killers experienced extreme press and public antagonism. Sweden has shown a similar inclusive approach towards offenders [28, 45], as Norval Morris ([57], p. 5) describes: 'the Swedish criminal or prisoner still remains a Swedish citizen meriting respect, continuing properly to enjoy a quite high standard of living and remaining part of the community'. Summarizing, one might expect less intergenerational transmission in Sweden, and this study adds to the knowledge on the particular risk factor of having a convicted parent in Sweden.

We investigate transmission separately for men and women for three theoretical reasons. First, one would expect transmission to be stronger along same-gender relationships. In the Cambridge Study in Delinquent Development, Farrington et al. [24] found stronger links between criminal behaviour between and within generations in same-gender relationships compared with opposite-sex relationships. Second, separating analyses by offspring gender is important, because boys and girls might react differently to stressful life events such as parental convictions [24]. In general, boys display more externalising problem behaviour such as delinquency, while girls have more internalising problems such as anxiety and depression [15, 68, 69]. Following this, one might expect a stronger impact of parental crime on sons than on daughters. Third, it is important to distinguish between paternal and maternal crime. Most children are more exposed to their mother's behaviour. Furthermore, convicted women are unusual. Being such an exception might lead to more stigma in society, and official bodies such as the police might pay more attention to these women and their families (see also [9]). Convicted women may also be labelled as disturbed rather than criminal [38]. According to labelling theory, people will behave according to the label society attaches to them [53]. Additionally, Sherman ([72], p. 459) hypothesized that persistent 
police action might lead to 'defiance', a 'proud and angry emotion' that can result in antisocial behaviour. In line with this, one might expect intergenerational transmission from mothers to be stronger than from fathers.

Finally, we explore intergenerational transmission by using trajectory models. Hitherto, three studies have employed group-based trajectory modelling to study intergenerational transmission of crime. Using data from the Dutch CCLS Study, van de Rakt et al. [84] investigated trajectories of fathers and their children and found that offspring whose fathers belong to a more persistent trajectory group are more likely also to be in such a trajectory group. Besemer and Farrington explored intergenerational transmission in the Cambridge Study of Delinquent Development [8] as well as in the Dutch Transfive Study [6]. They estimated trajectories for fathers and their children and demonstrated that offspring of sporadic and chronic offenders had significantly more convictions than offspring of non-offenders. However, contrary to expectations based on taxonomic and intergenerational theories, chronic offending fathers did not have more chronic offending offspring than sporadically offending fathers. The results demonstrated strong intergenerational transmission of criminal behaviour, but it is the fathers having a conviction rather than their conviction trajectory that was related to offspring convictions. As far as known to the authors, no other studies have investigated intergenerational transmission of crime using group-based trajectory modelling. Since the previous studies reach different conclusions, it is essential to replicate this research. Moreover, we build upon these earlier studies employing group-based trajectory modelling, because we estimate one trajectory model for the full sample instead of estimating models for parent and child samples separately. By doing this, we can make more direct comparisons between parent and child trajectories.

These investigations are relevant to scholars interested in the mechanisms of intergenerational transmission. By employing group-based trajectory modelling, one can explore the impact of the timing and intensity of parental crime. In studying intergenerational transmission, it is vital to not only focus on whether parents have a conviction but also investigate the intensity and timing of parental crime. When studying development of behaviour, it is important to focus on criminal career parameters such as the age of onset, peak of offending age and conviction frequency [11, 52, 65]. First, based on explanations for intergenerational transmission, one would expect stronger intergenerational transmission when parents' intensity of crime is higher. If, for example, social learning were the mechanism responsible for transmission, children whose parents are more frequent offenders would have an increased risk of offending themselves [8]. Thornberry [78] also hypothesizes that more frequent and persistent offenders will transmit criminal behaviour to their children more strongly. Parents' delinquency has a strong effect on their own development, transition into adult roles, parenting styles and thereby the effectiveness of their parenting, which in turn will increase the risk that their children will develop criminal behaviour.

Second, regarding timing, based on criminological theories, one would expect more intergenerational transmission when parents show criminal behaviour later in life. Deviant behaviour peaks in adolescence [66], and it is rather common to display some delinquency during this period. It is, however, a sign of greater deviance if such behaviour continues after adolescence or starts in adulthood. Moffitt [56] describes this as adolescence-limited versus life-course-persistent offenders. As discussed by Besemer and Farrington [8], based on Moffitt's theory, one would expect 
intergenerational transmission to be stronger for life-course-persistent than for adolescence-limited parents for three reasons. First, Moffitt's theory explains life-course persistents' antisocial behaviour as having a biological origin, and this hereditary basis could be passed on to children. Second, a life-coursepersistent parent will display more antisocial behaviour and will therefore be a stronger criminal role model for children according to social learning theories. Third, police and justice bodies will be more strongly biased against families with life-course-persistent offenders (see also [9]).

Knowledge of which parents are most likely to transmit crime to their children is also highly relevant for prevention strategies. Rehabilitation and prevention is most effective when programs follow three principles of effective correctional treatment [3-5, 29-31, 75]. The risk principle states that interventions should be given only to high-risk offenders, because they have many criminogenic needs that can be easily targeted. Low-risk offenders, in contrast, are actually more likely to stop offending if they do not become involved in the justice system through prison sentences. One could apply a similar thing to prevention programs where it is most effective to focus on children who have the highest risk of offending later in life. If children of more persistent offenders have a higher risk of offending, one should focus prevention efforts on these children.

\section{Hypotheses}

Our research questions above lead to the following specific hypotheses:

1. Intergenerational transmission is stronger for same-gender relationships.

2. Intergenerational transmission is stronger for sons than for daughters.

3. Intergenerational transmission is stronger from mothers than from fathers (because a criminal mother is more deviant than a criminal father).

And specifically using trajectory analyses:

4. Children whose fathers have a more persistent offending trajectory are more likely to have a conviction.

5. Convicted children of more persistent offending fathers will have more convictions than convicted children of more sporadic offending fathers.

6. Non-offending father trajectories tend to predict non-offending child trajectories.

7. The different types of offending father trajectories predict similar types of children offending trajectories.

\section{Method}

\section{Sample}

We used data from the Stockholm Life Course Project (SLCP), a Swedish longitudinal project with individuals with and without a delinquent background. The project centres around three different groups: the Clientele boys, the Skå boys and the $\$ 12$ Youth Group. First, the Clientele boys (born in Stockholm between 1943 and 1951) consist of 
two groups: 192 boys who were registered as having at least one conviction by age 15 and a control sample of 95 boys who did not have a conviction by age 15 . $^{2}$ The control sample was matched to every second delinquent boy based on social group (high or low), family type (high or low risk), residential area in Stockholm and age [70]. The delinquent and non-delinquent boys were extensively examined within the 1956 Clientele Study of Juvenile Law breakers and were followed up for interviews during the 1980s ([76]). The SLCP constitutes the second follow-up of these boys.

Second, the Skå population consists of 100 boys (born in Stockholm between 1941 and 1954) who had been sent to the 'Skå institution' for treatment of antisocial problems. ${ }^{3}$ The philosophy of the Skå institution was that children should be treated in groups that closely resembled families. Therefore, the institution consisted of nine two-story buildings that each housed seven children, as well as an employed man and woman who served as the mother and father of the family. Around the houses, a small community was built with therapy buildings, a hospital and a school. Later, this setup was changed in order to include the biological families of the children as the family gained importance in the treatment [49].

These boys were extensively examined by Jonsson [49]. The boys were between 7 and 16 years of age at the time of admission to the institution, and the majority were admitted due to delinquency. We have data on 97 of the 100 boys.

Third, the $\$ 12$ Youth Group ${ }^{4}$ was originally based on a sample of 420 boys and girls (born 1969-1974). These youth were subject to interventions by the Local Social Services in Stockholm County in the early 1990s. Two hundred sixty-seven were placed in residential treatment homes, mostly because they were involved in juvenile delinquency. For the remaining 153, the Social Service Board applied for admission to residential treatment homes, but they were denied a placement for various reasons, mostly due to the institutions being fully occupied. These boys had slightly lower levels of offending and other social problems than the ones who were sent to the institutions (Axelsson \& Sarnecki, forthcoming). For more detailed information regarding the Stockholm Life Course Project, see Carlsson and Sarnecki [16].

Due to changes in the system of registration of offences in Sweden during 1965, there are two sources of information about offending; before and after 1965. We have complete offending data for all of the Clientele and Skå boys but not for the control samples. It was deemed as not being worth the costs of gathering them. However, we have been able to add individuals from the control samples if they were born in 1950 or after. For these, we have complete offending data. We therefore were able to add some of the shadow boys and siblings to both the shadow boys and Stockholm boys to G2. Four children, two in G2 and two in G3, had been adopted.

\footnotetext{
${ }^{2}$ The Clientele sample also included shadow boys, a sample of 192 boys matched to the clientele boys based on the same variables as the control group. These were only followed through official registries. The control boys were subjected to the same extensive examinations as the clientele boys. We cannot include the shadow boys in G2 in the intergenerational analyses, because we do not have information about their parents' offending.

${ }^{3}$ As with the Clientele boys, there is a control group for the Skå boys: The Stockholm boys are a representative sample of 222 boys born in Stockholm around the same time as the Skå boys. Similar to the Clientele controls, we do not have their parents' offending histories and thus we cannot include these control boys in our analyses.

${ }^{4}$ The name refers to Section 12 of the Swedish Act ([51]), with Special Provisions for Care of the Young People, which gives authorities the right to place people under 21 in compulsory institutional treatment.
} 
Sweden has excellent administrative records of crime, and we had access to criminal records not only of the Clientele, Skå, and $\S 12$ Youths but also of their parents, siblings, children, grandchildren and the sibling's children and grandchildren. Therefore, the sample consists of delinquent as well as non-delinquent individuals. Although a conviction is not synonymous with delinquent behaviour, the majority of the sample does not have a conviction and the proportion of people convicted is very similar to other longitudinal intergenerational samples (see e.g. Besemer [6] for the Cambridge Study in Delinquent Development and the Dutch Transfive Study). Figure 1 provides a graphical overview of all the different samples, the number of people in each group and their average year of birth. We define G1 as the parents of the Clientele and Skå boys: G2 consists of the Clientele and Skå boys as well as their brothers and sisters and the $\S 12$ Youth's parents; G3 consists of the $\S 12$ Youths and their siblings and the offspring of the Clientele and Skå boys and of their siblings. Although women were not included in the original Clientele or Skå study, we also have data on women connected to these samples. In the original $\S 12$ Youth study, women were included. This gives us the possibility to study three generations of women as well as men. Due to the low prevalence of registered offending among the women, we were unable to investigate trajectories of offending for women, but we did examine intergenerational transmission without the use of trajectories.

We only have information about criminal offending for both parents for $131(4.6 \%)$ of the children in G3. When the project was initiated, the decision was made not to acquire data on the partners of the G2 individuals. We therefore only know criminal offending for one parent for the majority of the sample. Therefore, we decided to focus on transmission from fathers and mothers separately.

\section{Measures}

Measures on criminal conviction were gathered from the Swedish national archives for offences committed before 1965 and from the National Council for Crime Prevention for offences after 1965. Sweden implemented a new penal code in 1965. According to

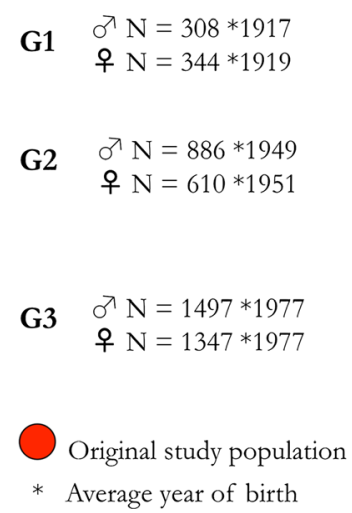

\section{Clientele and Skå}

$\$ 12$ Youth

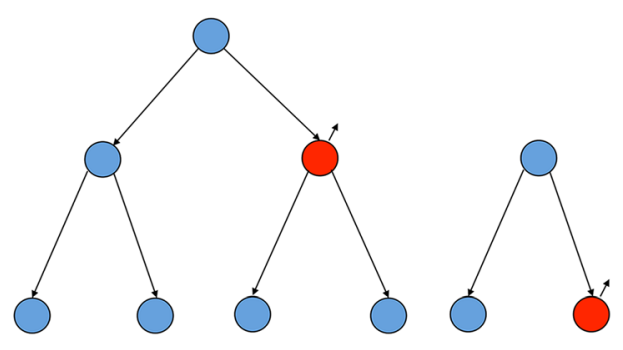

Fig. 1 Design of the Stockholm Life Course Project 
von Hofer [42], the changing of penal codes led to an increase in sanctions available, because of a stronger focus on individual prevention in Sweden during that period. The notion of treating an offender became more important than to punish them. In the mid-1990s, however, the law was changed again and the punishment became more important than treatment of offenders [77].

Since we only use the number of convictions, the differences between the penal codes should be marginal. Every offence type, except traffic violations, and the most trivial offences such as drunkenness were included. The date of the offence was used to calculate the number of convictions during a calendar year. If no commission date was available, we used the date of conviction instead. We only counted one conviction per day. This rule was adopted so that each separate behavioural act could yield only one offence; if all offences had been counted, the number of offences would have been greater than the number of criminal behavioural acts, resulting in an overestimation of criminal behavioural acts.

Table 1 shows descriptive statistics for the samples used. In our sample of 2691 men, $1022(38.0 \%)$ had a conviction between their 15th and 40th birthdays. Of the convicted men, $32.4 \%$ had one conviction, $14.1 \%$ had two convictions, $19.2 \%$ had three to five convictions, $11.9 \%$ had six to nine convictions, $13.8 \%$ had 10 to 20 convictions and $8.6 \%$ had 21 convictions or more. For the 2301 women in our sample, 326 (14.2\%) had been convicted at least once. Of the convicted women, $56.1 \%$ had been convicted once, $17.5 \%$ had two convictions, $15.6 \%$ had three to five convictions, $4.3 \%$ had six to nine convictions, $4.0 \%$ had 10 to 20 convictions and $2.5 \%$ had 21 convictions or more.

The differences between convictions in the generations are worth noting. The proportion of people convicted in G1 is much lower than in G2 and G3. This generation was born at a period in which offending was at its lowest in Sweden. It is therefore reasonable to expect offending in this generation to be lower than in the subsequent ones [41]. Moreover, as expected, women in the different samples have a much lower proportion of convictions than men.

\section{Data Analysis}

\section{Semi-parametric Group-Based Trajectory Modelling}

Group-based modelling was performed using the SAS macro proc traj [46, 47]. Rather than assuming an average age-crime curve for every individual, Nagin and Land's [63]

Table 1 Descriptive statistics for the sample

\begin{tabular}{|c|c|c|c|c|c|c|c|}
\hline & $\begin{array}{l}\text { G1 } \\
\text { males }\end{array}$ & $\begin{array}{l}\text { G1 } \\
\text { females }\end{array}$ & $\begin{array}{l}\text { G2 } \\
\text { males }\end{array}$ & $\begin{array}{l}\mathrm{G} 2 \\
\text { females }\end{array}$ & $\begin{array}{l}\text { G3 } \\
\text { males }\end{array}$ & $\begin{array}{l}\text { G3 } \\
\text { females }\end{array}$ & $\begin{array}{l}\text { Total } \\
\text { sample }\end{array}$ \\
\hline$N$ of individuals & 308 & 344 & 886 & 610 & 1497 & 1347 & 4992 \\
\hline $\begin{array}{l}\text { Proportion with a conviction between ages } \\
15 \text { and } 40\end{array}$ & $7.1 \%$ & $2.9 \%$ & $45.0 \%$ & $16.2 \%$ & $40.1 \%$ & $16.1 \%$ & $27.0 \%$ \\
\hline $\begin{array}{l}\text { Average number of convictions for those } \\
\text { with a conviction }(15-40)\end{array}$ & 2.27 & 1.20 & 5.28 & 2.98 & 8.11 & 3.03 & 5.95 \\
\hline
\end{tabular}


semi-parametric group-based modelling approach summarizes the multitude of longitudinal offending patterns into a manageable number of groups of individuals who display similar behavioural trajectories. This technique allows variation between groups of individuals and allows for different age-crime curves. See Nagin [59] for a non-technical overview of the group-based modelling technique.

It is important to understand that the semi-parametric, group-based trajectory methodology is not a reflection of reality but rather a way of summarizing or describing the data. It does not mean that these individuals literally follow the trajectory group they have been assigned to. The trajectory for each group should be viewed as an average trajectory of all the individual trajectories in that group. The technique of trajectory modelling should be used as a heuristic tool, and the results should not be perceived as the truth [60, 62-64, 73, 74].

The goal of trajectory analysis is to find the optimal solution where groups of individuals with distinctive individual-level trajectories can be identified but where adding an additional group to the model offers no extra explanatory power [61]. This is done using formal statistical criteria and theoretical judgment. A test used to determine the optimal number of groups is the Bayesian information criterion (BIC) (see e.g. [8]). However, Skardhamar [74] and Nagin [61] note that model selection needs to be guided by theory, not just statistical criteria. Skardhamar [74] describes how many studies using trajectory modelling try to identify the highest possible number of groups instead of focusing on the shape and slope of the groups (see also [19]). Model selection should not be done by using only the BIC; it is important to check the shape and slope of the different trajectories, and groups that are not distinct from another or do not have a reasonable interpretation are of little use. Nagin [61] suggests that a simpler model is preferred over adding complexity to the interpretation.

After estimating which model describes the sample best, it is possible to use the posterior probability of group membership to measure the probability that an individual might belong to a specific trajectory group [61]. Using the highest probability, proc traj will assign every individual to a specific group. ${ }^{5}$

We used a zero-inflated Poisson model, because convictions are relatively rare events and therefore the distribution of the number of convictions is skewed; i.e. there are many people with zero convictions or a low number of convictions. Using an inflation parameter allows subjects to have "temporary"

\footnotetext{
$\overline{5}$ This is one way of assigning individuals to groups, which Goodman [33] calls modal assignment. Goodman also demonstrates an approach (for Latent Class Analysis) in which people with a similar response pattern are randomly assigned to a class to get the proportions of the probabilities of group membership. For example, if individuals with a certain response pattern have a probability of .8 to be in a certain class $\mathrm{A}$ and .2 to be in a certain class B, following the modal assignment, all these individuals would be classified as class A. Following the random assignment, $80 \%$ of these people will be classified as A, $20 \%$ as B. Modal assignment minimizes incorrect classifications, while random assignment approximates the proportion of individuals in each group to be the posterior probability of group membership. Random assignment takes the uncertainty of group classification into account. When we assign people to classes in proc traj to be able to calculate with them, modal assignment is used and the group uncertainty is ignored. Currently, however, this is the only way in proc traj to assign people to classes.
} 
spells of non-offending without recording a change in their overall rate of offending' ([14], p. 138).

Due to reasons of personal integrity and security, Statistics Sweden does not provide dates of birth for the individuals, only birth years. We therefore used calendar years and calculated the number of convictions during the entire calendar year of a certain age. For instance, if an individual was born in 1982 and committed ten offences in 1997, these were calculated as committed at age 15 .

If the individual was incarcerated during the full year, those years are coded as missing. If people passed away during the observation period i.e. before the age of 40 , this was controlled for by coding subsequent years as missing. These missing years did not contribute to estimating the trajectories. According to Eggleston et al. [18], controlling for mortality is important because of the problem with false desistance. If we do not control for mortality, we may draw conclusions about desisting from crime, when in fact the person had died. Twenty-three people passed away before the age of 15 and were excluded from the sample in this paper.

In the SLCP, we have a large number of incarcerations, but very few of the individuals were incarcerated for an entire year or more. Incarcerations in Swedish prisons tend to be short and rarely exceed 6 months. Given that $29.6 \%$ of our sample had been incarcerated at least once and offending is less likely to happen when offenders are incarcerated, we corrected for time spent incarcerated. Next to estimating a model uncorrected for incarceration, we estimated models where the corrected rate of offending was calculated with the following formulas [8, 87]:

Corrected rate of offending ${ }_{t j}=$ off $_{t j} /$ Exposure $_{t j}$, where

1. Exposure $_{t j}=1-($ Number of days incarcerated $/ 365)$ and

2) Exposure $_{t j}=1-($ Number of days incarcerated $/ 730)$,

where $j$ is the respondent and $i$ is the year of observation

For example, in the first model, if someone had been incarcerated for half of the year (e.g. 182 days), the exposure would be 0.5 and the corrected rate of offending would be twice the offending rate. In the second model, if someone had been incarcerated for half of the year, the exposure would be 0.75 and the corrected rate of offending would be 1.33 times the offending rate. The first model, where exposure can vary from 1 (no incarceration) to 0 (365 days of incarceration), produced a highly inflated high persistent offender group (where most incarcerations took place), which was not visible in the other models. Van der Geest et al. [87] argue that adjusting for 356 days in the model results in extremely high rates of offending for a number of individuals, because dates for offences, conviction and incarceration overlap. This is also very common in our sample. Using a 'weakened' correction in the second model takes into account time spent incarcerated, but does not disproportionally inflate one offending group. For each of the three models, we also investigated intergenerational transmission, and the results were mostly similar. In this paper, we report the second model that corrects for offending with a minimum exposure of 0.5 . 


\section{Generalized Estimating Equations}

After assigning people to classes, we used generalized estimating equations (GEEs) in SPSS to investigate our research questions [55, 89]. Since part of the sample consisted of siblings, there is clustering within families. As a consequence, conventional statistics are inappropriate, because these do not take into account the dependencies between cluster members [2]. GEE, however, uses this within-cluster similarity. It weights each cluster of data according to the within-cluster correlation [37]. When there is no correlation between family members, the cluster receives a weight of 1 and cluster members are treated as though they were independent subjects. Highly correlated siblings receive a lower weight. Using these weights, GEE then analyses the relationships between the variables considering the dependencies within clusters. GEE is especially useful in cases where there is a large number of families, consisting of fewer than 10 members [54]. Within GEE, it is possible to choose different analytical models. We used logistic regression for the dichotomous outcomes. For hypothesis 6 , we used negative binomial regression, because the dependent variable frequency of offspring offending was highly skewed: many people had only one conviction. We used ordinal probit regression to compare fathers' and offspring's trajectories for hypothesis 7 which gives a $\chi^{2}$. Pearson's $\chi^{2}$ test examines whether two categorical variables, in this case the father and child's trajectory memberships, are related to each other [25]. For hypothesis 8 and 9, adjusted standardized residuals (ASRs) were calculated to identify which groups were responsible for significant differences. It is not possible to calculate ASRs using GEE. To account for the fact that our sample consisted of fathers with multiple children, ASRs were calculated for samples where one child was randomly chosen for every father. The ASR values reported are the mean value of 50 randomly taken samples. A residual greater than 2.0 was considered to indicate a significantly higher proportion, and a residual less than -2.0 was taken to indicate a significantly lower proportion than expected if there was no relationship between fathers' and offspring's trajectory groups $[13,36]$.

\section{Results}

\section{Intergenerational Transmission}

Before using group-based trajectory modelling, we investigated the extent of intergenerational transmission in the SLCP.

\section{Intergenerational Transmission Is Stronger for Same-Gender Relationships}

Father-Son versus Father-Daughter Table 2 shows that sons of convicted fathers have increased odds of offending around 1.9 times $(\mathrm{OR}=1.9,95 \%$ CI 1.4-2.4) compared with sons whose fathers have not been convicted. The odds for daughters of convicted fathers are increased by about 3.5 times 
Table 2 Intergenerational transmission of criminal behaviour for fathers only (ignoring whether mothers had a conviction)

\begin{tabular}{|c|c|c|c|c|c|c|}
\hline \multirow[b]{3}{*}{ Offspring convicted } & \multicolumn{2}{|c|}{ Father not convicted } & \multicolumn{2}{|c|}{ Father convicted } & \multicolumn{2}{|l|}{ GEE } \\
\hline & \multicolumn{2}{|l|}{$15-40$} & \multicolumn{2}{|l|}{$15-40$} & \multirow[b]{2}{*}{ OR } & \multirow[b]{2}{*}{$95 \% \mathrm{CI}$} \\
\hline & $N$ total & $\%$ Convicted & $N$ total & $\%$ Convicted & & \\
\hline Total all & 1675 & 24.1 & 787 & 37.7 & 1.954 & $1.588-2.405$ \\
\hline Total sons & 1000 & 34.7 & 414 & 49.8 & 1.863 & $1.436-2.419$ \\
\hline Total daughters & 675 & 8.4 & 373 & 24.4 & 3.502 & $2.406-5.099$ \\
\hline G1-G2 all & 750 & 32.5 & 87 & 43.7 & 1.647 & $0.965-2.809$ \\
\hline G2-G3 all & 925 & 17.3 & 700 & 37.0 & 2.821 & $2.182-3.646$ \\
\hline
\end{tabular}

$(\mathrm{OR}=3.5,95 \% \mathrm{CI} 2.4-5.1)$. This difference is significant $(d=0.631,95 \% \mathrm{CI}$ $0.174-1.088)^{6}$.

Mother-Son versus Mother-Daughter (Table 3) Sons of convicted mothers have 2.7 times increased odds of a conviction ( $\mathrm{OR}=2.7,95 \%$ CI 1.9-3.9), while daughters have 3.2 times increased odds $(\mathrm{OR}=3.2,95 \% \mathrm{CI} 2.0-5.2)$. These odds ratios are not significantly different from each other $(d=0.173,95 \%$ CI -0.439-0.786).

Father-Son versus Mother-Son Comparing the odds ratio for fathers and sons $(\mathrm{OR}=1.9,95 \%$ CI 1.4-2.4) with the odds ratio for mothers and sons

\footnotetext{
${ }^{6}$ Throughout this paper, odds ratios were compared following [1] using the formula:
}

$$
z=\frac{d}{S E(d)}
$$

where $d=L O R 1-L O R 2$ and where $L O R 1=\operatorname{Ln}(1$ st odds ratio), $L O R 2=\operatorname{Ln}(2$ nd odds ratio).

$$
\begin{gathered}
S E(d)=\sqrt{S E_{1}^{2}+S E_{2}^{2}} \\
S E_{1}=\frac{\text { width } \operatorname{Ln}\left(C I_{1}\right)}{2 \times 1.96} \text { and } S E_{2}=\frac{\text { width } \operatorname{Ln}\left(C I_{2}\right)}{2 \times 1.96}
\end{gathered}
$$

Width $\operatorname{Ln}(\mathrm{CI})=\operatorname{Ln}($ Higher value of $95 \% \mathrm{CI})-\operatorname{Ln}($ Lower value of $95 \% \mathrm{CI})$

$\mathrm{CI}(d)=d \pm 1.96 \times \mathrm{SE}(d)$. 
Table 3 Intergenerational transmission of criminal behaviour for mothers only (ignoring whether fathers had a conviction)

\begin{tabular}{|c|c|c|c|c|c|c|}
\hline \multirow[b]{3}{*}{ Offspring convicted } & \multirow{2}{*}{\multicolumn{2}{|c|}{$\frac{\text { Mother not convicted }}{15-40}$}} & \multirow{2}{*}{\multicolumn{2}{|c|}{$\frac{\text { Mother convicted }}{15-40}$}} & \multicolumn{2}{|l|}{ GEE } \\
\hline & & & & & & \\
\hline & $N$ total & $\%$ Convicted & $N$ total & $\%$ Convicted & OR & $95 \% \mathrm{CI}$ \\
\hline Total all & 1942 & 33.0 & 292 & 55.8 & 2.631 & $1.970-3.513$ \\
\hline Total sons & 1196 & 44.4 & 178 & 68.0 & 2.717 & $1.869-3.949$ \\
\hline Total daughters & 746 & 14.6 & 114 & 36.8 & 3.231 & $1.989-5.249$ \\
\hline G1-G2 all & 846 & 34.5 & 40 & 42.5 & 1.414 & $0.487-4.107$ \\
\hline G2-G3 all & 1096 & 31.8 & 252 & 57.9 & 3.045 & $2.239-4.141$ \\
\hline
\end{tabular}

$(\mathrm{OR}=2.7,95 \%$ CI 1.9-3.9) shows that transmission from mother to son is not significantly stronger than from father to son $(d=0.377,95 \% \mathrm{CI}-0.079-0.833)$.

Mother-Daughter versus Father-Daughter The odds ratios for mothers and daughters $(\mathrm{OR}=3.2,95 \% \mathrm{CI} 2.0-5.2)$ and fathers and daughters $(\mathrm{OR}=3.5,95 \% \mathrm{CI}$ $2.4-5.1)$ are not significantly different $(d=0.108,95 \%$ CI $-0.505-0.720)$.

Overall, the results do not provide strong support for hypothesis 1 and some results actually suggest an opposite pattern: transmission seems to be stronger for daughters versus sons of convicted fathers.

\section{Intergenerational Transmission Is Stronger for Sons than for Daughters}

Comparing sons and daughters with a convicted father shows that the odds ratio for daughters $(\mathrm{OR}=3.5)$ is significantly larger compared with sons $(\mathrm{OR}=1.9) \quad(d=0.631,95 \% \mathrm{CI}-0.174-1.088)$. For children with convicted mothers, the odds ratio for daughters $(\mathrm{OR}=3.2)$ is not significantly larger than for sons $(\mathrm{OR}=2.7)(d=0.173,95 \% \mathrm{CI}-0.439-0.786)$. The results show a pattern opposite to the hypothesis: it seems that intergenerational transmission is stronger for daughters, although this difference is not significant for convicted mothers.

Intergenerational Transmission Is Stronger from Mothers Than from Fathers (Because a Criminal Mother Is More Deviant Than a Criminal Father)

Offspring of convicted mothers show increased odds of a conviction (Table 3: $\mathrm{OR}=2.6,95 \%$ CI 2.0-3.5) compared with fathers (Table 2: OR $=2.0,95 \% \mathrm{CI}$ $1.6-2.4)$, but this is not a significant difference $(d=0.297,95 \% \mathrm{CI}-0.058-0.653)$. This does not support hypothesis 3 that transmission from mothers is not stronger than from fathers. 


\section{Offending Trajectories}

We modelled all individuals together to have the same trajectories for G1, G2 and G3. In previous studies comparing trajectories, each subsample or generation (fathers, sons and grandsons) was modelled separately. The first step in estimating the trajectory model is to decide on the number of groups. We first estimated trajectory models with the full sample, including non-offenders. However, the resulting model included a group with non-offenders as well as offenders with one offence only. We wanted a distinctive non-offending group, and thus, we continued estimating models without the non-offenders. When estimating models, the BIC values for the models continued to decrease up to ten groups. A model with ten groups is not useful and especially not because the number of people in each group was extremely low. Moreover, additional groups that were identified in subsequent models did not add any new information to the model (see also [74]). We decided to use a model with four offending groups, because this model has four distinct offending groups. Adding a fifth offending group to the model created an offending group very similar to one of the other groups, not adding anything meaningful to the model while decreasing the number of people in the groups.

Next, we estimated which shape of the trajectories would give the best fit. A trajectory shape can be zero (non-offending), flat, linear, quadratic or cubic (for more technical information, see [61]). For our model, the best fit for the data was one linear, one cubic and two quadratic groups (see Appendix for the BIC values). The non-offenders were added after the estimation was completed. Subsequently, the final model consists of five groups, four offender groups and one non-offender group.

The resulting trajectory model can be found in Fig. 2. Non-offenders (NO) comprised the largest part of the sample with $62.0 \%$. The offending groups are labelled as follows: low rate offenders (LR, $26.5 \%)$; desisters (D, $4.8 \%$ );

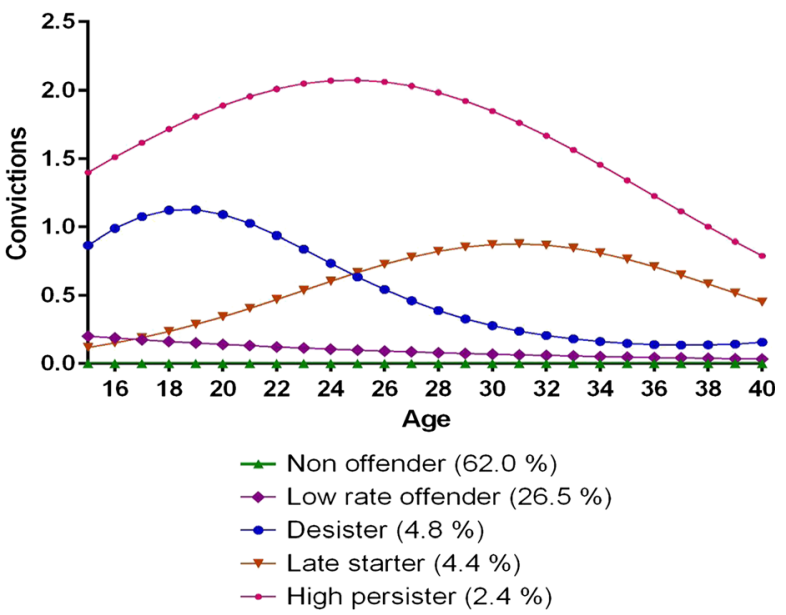

Fig. 2 Trajectory model controlling for partial-year incarceration: age-crime curves for the men of the SLCP 
late starting offenders (LS, $4.4 \%$ ) and high persisters (HP, $2.4 \%$ ). On average, low rate offenders had 2.3 convictions between age 15 and 40 , desisters 13.2 convictions, late starting offenders 12.9 convictions and high persisters 34.3 convictions.

Interestingly, we find that the high persisting group is almost entirely made up of G3 men. This fits the pattern shown in Table 1 regarding conviction rates per generation: the convicted men in G3 have a higher average number of convictions compared with G1 or G2. The HP group consists of 64 individuals in total, of which none are from G1, 4 are from G2 and 60 are from G3. With such a small sample of G2 high persisting men, it is not reasonable to investigate transmission from this group, especially considering that only one of the four G2 men was a father. The late starter group, on the other hand, consists mostly of G2 and G3 men, but hardly any G1 men: only one G1 father is included in the group, while 77 come from G2 and 40 from G3.

\section{Offspring Offending Per Father Trajectory Group}

Children Whose Fathers Have a More Persistent Offending Trajectory Have a Higher Risk of a Conviction

Children of fathers in an offending trajectory (LR, D or LS) all have higher odds of a conviction compared with children with non-offending fathers (Table 4). However, when looking at children of fathers in an offending trajectory, we find only one significant difference in the odds of offending:

Table 4 Prevalence of offspring convictions between ages 15-40 per father offending trajectory group

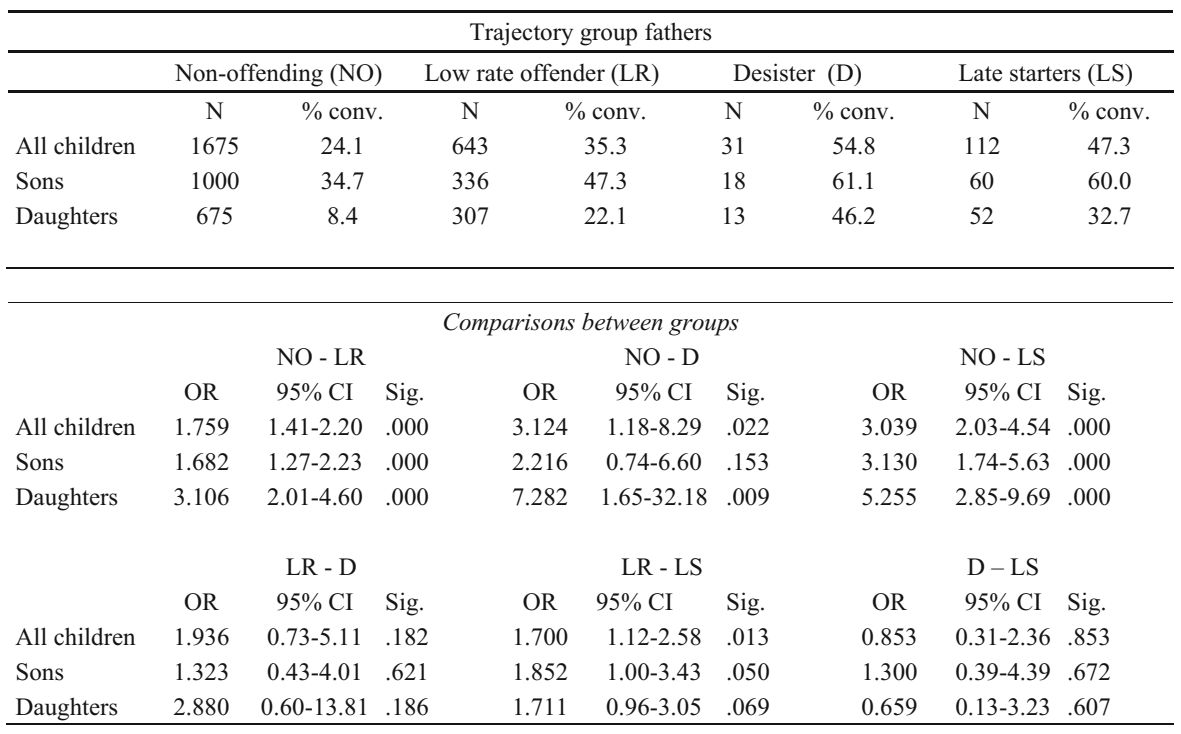

$95 \%$ CI $95 \%$ confidence interval, $N$ number of children, $O R$ odds ratio 
$35.3 \%$ of children of low rate offenders (LR) versus $47.3 \%$ of children of late starters (LS) are convicted themselves $(\mathrm{OR}=1.7,95 \% \mathrm{CI} 1.1-2.6)$. Thus, we find only partial support for hypothesis 4 .

Convicted Children of More Persistent Offending Fathers Will Have More Convictions Than Convicted Children of More Sporadic Offending Fathers

When looking at the conviction rate for those children with a conviction, the results (Table 5) demonstrate that children of fathers in an offending trajectory tend to have pretty similar conviction rates as children of non-offending fathers. The only group that tends to have a slightly higher conviction rate is the group of children from Late Starting fathers $(C R=9.43)$. Their conviction rate is significantly higher than that of children of non-offending fathers $(B=0.558,95 \%$ CI $0.17-0.94)$ and of low-rate offending fathers $(B=0.448$, $95 \%$ CI $0.04-0.86)$. The overall pattern of results does not support hypothesis 5 .

\section{Intergenerational Resemblance of Offending Trajectories}

Finally, we compared father and son offending trajectories. The proportions of sons per group of fathers and the ASRs are presented in Table 6. The overall association between the father and the son offending trajectories was significant when

Table 5 Average number of convictions for offspring conviction with a conviction between ages $15-40$ per father offending trajectory group

\begin{tabular}{|c|c|c|c|c|c|c|c|c|c|c|}
\hline \multicolumn{11}{|c|}{ Trajectory group fathers } \\
\hline & \multicolumn{3}{|c|}{ Non-offending (NO) } & \multicolumn{3}{|c|}{ Low rate offender (LR) } & \multicolumn{2}{|c|}{ Desister (D) } & \multicolumn{2}{|c|}{ Late starters (LS) } \\
\hline & $\mathrm{N}$ & \multicolumn{2}{|l|}{$\mathrm{CR}$ (SD) } & $\mathrm{N}$ & \multicolumn{2}{|c|}{$\mathrm{CR}$ (SD) } & $\mathrm{N}$ & $\mathrm{CR}(\mathrm{SD})$ & $\mathrm{N}$ & $\mathrm{CR}(\mathrm{SD})$ \\
\hline All children & 404 & \multicolumn{2}{|l|}{$5.52(8.40)$} & 227 & \multicolumn{2}{|c|}{$6.00(9.52)$} & 17 & $5.47(7.69)$ & 53 & $9.43(10.74)$ \\
\hline Sons & 347 & \multicolumn{2}{|c|}{$6.07(8.81)$} & 159 & \multicolumn{2}{|c|}{$7.35(10.65)$} & 11 & $6.91(9.24)$ & 36 & $0.50(10.10)$ \\
\hline Daughters & 57 & \multicolumn{2}{|l|}{$2.16(3.87)$} & 68 & \multicolumn{2}{|c|}{$2.85(4.86)$} & 6 & $2.83(2.40)$ & 17 & $7.18(12.00)$ \\
\hline \multicolumn{11}{|c|}{ Comparisons between groups } \\
\hline & \multicolumn{3}{|c|}{$\mathrm{NO}-\mathrm{LR}$} & & \multicolumn{3}{|c|}{$\mathrm{NO}-\mathrm{D}$} & \multicolumn{3}{|c|}{$\mathrm{NO}-\mathrm{LS}$} \\
\hline & $B$ & $95 \% \mathrm{CI}$ & Sig. & & $B$ & $95 \% \mathrm{CI}$ & Sig. & $B$ & $95 \% \mathrm{CI}$ & Sig. \\
\hline All children & 0.107 & $-0.16-0.38$ & .439 & & 0.100 & $-0.66-0.87$ & .798 & 0.558 & $0.17-0.94$ & .004 \\
\hline Sons & 0.208 & $-0.08-0.50$ & .156 & & 0.176 & $-0.63-0.98$ & .668 & 0.572 & $0.20-0.95$ & .003 \\
\hline \multirow[t]{3}{*}{ Daughters } & 0.283 & $-0.33-0.90$ & .364 & & 0.225 & $-0.45-0.90$ & .515 & 1.187 & $0.28-2.10$ & .010 \\
\hline & \multicolumn{3}{|c|}{ LR - D } & & \multicolumn{3}{|c|}{$\mathrm{LR}-\mathrm{LS}$} & \multicolumn{3}{|c|}{$\mathrm{D}-\mathrm{LS}$} \\
\hline & B & $95 \% \mathrm{CI}$ & Sig. & & $B$ & $95 \% \mathrm{CI}$ & Sig. & $B$ & $95 \% \mathrm{CI}$ & Sig. \\
\hline All children & -0.017 & $-0.80-0.76$ & .966 & & 0.448 & $0.04-0.86$ & .032 & 0.376 & $-0.43-1.18$ & 8.362 \\
\hline Sons & -0.033 & $-0.86-0.79$ & .938 & & 0.363 & $-0.05-0.78$ & .084 & 0.385 & $-0.47-1.24$ & 4.375 \\
\hline Daughters & 0.015 & $-0.75-0.78$ & .970 & & 0.917 & $0.04-1.80$ & .041 & 0.912 & $-0.09-1.92$ & 2.075 \\
\hline
\end{tabular}

$95 \%$ CI $95 \%$ confidence interval, $C R$ conviction rate, $N$ number of children, $S D$ standard deviation 
Table 6 Resemblance between fathers and sons: proportion of sons per father group and adjusted standardized residuals

\begin{tabular}{|c|c|c|c|c|c|c|}
\hline \multicolumn{7}{|l|}{ Father's trajectory } \\
\hline Son's trajectory & & Non-offender & Low-rate offender & Desister & Late starter & Total \\
\hline \multirow[t]{3}{*}{ Non-offender } & Count & 653 & 177 & 7 & 24 & 861 \\
\hline & Percent & 65.3 & 52.7 & 38.9 & 40.0 & 60.9 \\
\hline & ASR & $3.3^{*}$ & $-2.2^{*}$ & -0.4 & $-2.4^{*}$ & \\
\hline \multirow[t]{3}{*}{ Low-rate offender } & Count & 256 & 109 & 8 & 17 & 390 \\
\hline & Percent & 25.6 & 32.4 & 44.4 & 28.3 & 27.6 \\
\hline & ASR & -1.0 & 1.0 & 0.4 & 0.0 & \\
\hline \multirow[t]{3}{*}{ Desister } & Count & 24 & 24 & 1 & 6 & 55 \\
\hline & Percent & 2.4 & 7.1 & 5.6 & 10.0 & 3.9 \\
\hline & ASR & $-3.4^{*}$ & $2.2 *$ & 0.3 & $2.7 *$ & \\
\hline \multirow[t]{3}{*}{ Late starter } & Count & 51 & 12 & 1 & 6 & 70 \\
\hline & Percent & 5.1 & 3.6 & 5.6 & 10.0 & 5.0 \\
\hline & ASR & -0.2 & -0.1 & -0.2 & -0.7 & \\
\hline \multirow[t]{3}{*}{ High persister } & Count & 16 & 14 & 1 & 7 & 38 \\
\hline & Percent & 1.6 & 4.2 & 5.6 & 11.7 & 2.7 \\
\hline & ASR & $-2.7^{*}$ & 1.3 & -0.1 & $3.2 *$ & \\
\hline \multirow[t]{2}{*}{ Total } & Count & 1000 & 336 & 18 & 60 & 1414 \\
\hline & Percent & $100 \%$ & $100 \%$ & $100 \%$ & $100 \%$ & $100 \%$ \\
\hline
\end{tabular}

$\%$ percentage of column, per father group, ASR adjusted standardized residual $* p<.05$

testing the complete sample including all generations $\left(\chi^{2}=69.676, p<.000\right)$ indicating that father and offspring trajectories are related. This value, however, gives an indication of the overall association, but does not tell us about associations between specific offending trajectories, so we explore these associations further with hypotheses 6 and 7 .

\section{Non-offending Father Trajectories Tend to Predict Non-offending Child Trajectories}

We use ASRs to explore specific associations between father and son offending trajectories. Remember that a residual greater than 2.0 was considered to indicate a significantly higher proportion and a residual less than -2.0 was taken to indicate a significantly lower proportion than expected if there was no relationship between fathers' and offspring's trajectory groups [13, 36]. The results are presented in Table 6, and the ASRs demonstrate that non-offending (NO) fathers have a significantly higher proportion of NO sons (ASR=3.3). Moreover, NO fathers have a significantly lower proportion of desisting (D) and high persisting (HP) sons. These results support hypothesis 6 . 
The Different Types of Father Offending Trajectories Predict Similar Types of Children Offending Trajectories

Looking at the father offending trajectories, we see that low-rate offending (LR) and late starter (LS) fathers are less likely to have non-offending sons. Moreover, low-rate (LR) and late starting (LS) fathers are more likely to have desisting (D) sons. Also, late starter (LS) fathers are more likely to have HP sons. We do not necessarily find specific associations between the same offending trajectories (i.e. LR fathers and LR sons or LS fathers and LS sons). Summarizing, we do not find strong support for hypothesis 7. Father trajectories do not clearly predict son trajectories.

\section{Conclusion}

This study investigated intergenerational transmission in Sweden by using data from three generations of the Stockholm Life Course Project and by employing the group-based trajectory methodology. Overall, children of convicted fathers are about two times more likely to have a conviction compared with children of non-convicted fathers and children of convicted mothers are about 2.6 times more likely to have a conviction themselves. In the introduction, we hypothesized that Sweden might have less intergenerational transmission, because it is a welfare state aiming to equalize potential gaps between citizens, focusing on the family, with a strong public sector. However, this odds ratio for intergenerational transmission is similar to what has been found in other countries, such as England [21], the Netherlands [10, 83] and the USA [22]. This paper is not a direct cross-national comparison, and different studies cannot be easily compared with each other, but the current study shows that even in Sweden-a strong welfare state-one finds some degree of intergenerational transmission.

We did not find strong support that intergenerational transmission is stronger for same-gender relationships. Interestingly, opposite to what was predicted, it seems that intergenerational transmission was stronger for daughters compared with sons, although this difference was only significant for transmission from fathers. Similarly, transmission from mothers seemed slightly larger than transmission from fathers, but this difference was not significant.

Using trajectory analysis, we estimated offending trajectories for fathers and sons and studied the similarities between them. Although father and offspring trajectories look similar, the significant relationship can be explained by the observation that non-offending fathers are more likely to have non-offending sons. Fathers with more chronic offending trajectories do not necessarily predict sons with similar more chronic offending trajectories. The general conclusion from this study is that, surprisingly, the intensity of the father's career does not predict the intensity of the child's career. The results demonstrate a strong intergenerational transmission of criminal behaviour, but offspring convictions are related to the fact that fathers have a conviction rather than to what their conviction trajectory looks like. This conclusion is very similar to what has been found before in England with the Cambridge Study in Delinquent 
Development as well as in the Netherlands with the NSCR Transfive Study $[6,8]$. These results contradict van de Rakt et al. [84], who concluded that children of fathers in a more persistent trajectory group have a higher chance of belonging to a similar trajectory group. However, van de Rakt et al. [84] do not test whether the relationship between the trajectories of fathers and children is significant, nor do they give an effect size for this relationship.

Although we do not find that specific parent trajectories predict specific offspring trajectories, one interesting finding is that children of Late Starters have a higher conviction rate. As we discussed in the 'Introduction' section, there are several developmental and life-course criminological theories that hypothesized that there would be more intergenerational transmission when parents show criminal behaviour later in life. Late starting fathers might have been convicted during the child's life. Thus, there might be more social learning rather than when this behaviour happens before the child's birth. This relates to earlier studies that investigated timing of parental crime in the child's life and demonstrated that intergenerational transmission is stronger when parental crime occurs during instead of before the child's life [7, 85]. Moreover, this deviant behaviour might have impacted parenting skills, as Thornberry [78] hypothesized that parents' delinquency has a strong effect on their own development, transition into adult roles, parenting styles and thereby the effectiveness of their parenting, which in turn will increase the risk that their children will develop criminal behaviour.

\section{Limitations}

This study undoubtedly has limitations. First, only official data have been used and these suffer from a 'dark number' - the part of offending that is not measured by official statistics [26]. This means that we can study only a small part of people's total offending behaviour; we see the tip of the iceberg. People are likely to exhibit much more offending behaviour that is invisible to the police, and many people will never appear in official statistics even though they have exhibited criminal behaviour. Official convictions are only indicators of offending behaviour. Furthermore, the difference between official convictions and self-reported offending might be different for people with different conviction trajectories. Perhaps persistent offenders commit relatively more unseen offences compared with sporadic offenders, or, seemingly adolescent-limited offenders might have learned better how to avoid getting caught. We could not discriminate or measure the offending of fathers without a conviction. It is likely that there are fathers without a conviction who have actually shown some kind of delinquent behaviour. If one used self-report data on offending, this would lead to a finer gradation of the volume and timing of offending and it is possible that this would lead to different results. Therefore, it would be interesting to investigate trajectories of offending with self-reported data on offending behaviour.

Second, although we investigated intergenerational transmission for women, unfortunately, we were not able to estimate offending trajectories for women. It would be interesting to see whether investigating the intergenerational 
resemblance of conviction trajectories between mothers and children would yield the same conclusion as for fathers. It would be desirable to replicate this research with a data set that includes more (offending) women.

Third, as we also discussed in the 'Method' section, it is important to realize that describing groups of people in terms of their trajectories does not mean that these categories are a reflection of reality. Categorizing people using the semi-parametric, group-based trajectory methodology is a way of describing the data. It is certainly no proof of the existence of clearly distinguishable groups that follow exactly the trajectory of the group they have been assigned to. Offenders are not species that exclusively belong to a certain type. The technique of trajectory modelling should be used as a heuristic tool, and the results should not be perceived as the truth [60, 62-64, 73, 74].

\section{Strengths}

Despite these limitations, this study increased our knowledge on several points. First, this study used a relatively large sample. Second, we studied intergenerational transmission in Sweden. Third, this paper analysed whether intergenerational transmission was different for men versus women. This question is vital, as we explained in the 'Introduction' section, but has surprisingly hardly been investigated. Fourth, when using trajectory analysis, we estimated trajectories for the whole sample together instead of estimating trajectories for each generation separately. Previous studies estimating trajectories separately found no significant intergenerational transmission $[6,8,84]$. Theoretically, there are reasons to estimate trajectories separately (e.g. offending patterns might be different for different generations) or together (e.g. if one estimates generations together, parents and sons who show similar offending patterns will be grouped in the same trajectory). By estimating trajectories together, one can more easily compare parent and offspring trajectories. Moreover, trajectory estimates are more stable when sample sizes are larger. Even though this sample was large to begin with, the actual number of offending people per generation is not that large, so this is an important argument to estimate trajectories together. This paper adds to the trajectory literature because it is the first to estimate trajectories for three generations together. Fifth, the results show that children of convicted parents are roughly 2-2.6 times as likely to have a conviction themselves, even in a country like Sweden having mild and benign criminal justice policies.

As far as we know, there have been only four studies investigating intergenerational transmission by employing the semi-parametric, group-based trajectory methodology, including this one $[6,8,84]$. Since these studies reach different conclusions, it is vital that this research is replicated, preferably with large samples including many women.

Acknowledgments This project was supported by a Netherlands Organization for Scientific Research (NWO) Rubicon Fellowship to S.B. Data collection was funded by the Swedish National Board of Institutional Welfare. The authors have no competing or potential conflicts of interest. An earlier version of this article was presented at the 2014 Stockholm Criminology Symposium.

Compliance with Ethical Standards Ethical permission for the project was obtained by the regional ethics board in Stockholm and is in accordance with the 1964 Declaration of Helsinki and its later amendments. 


\section{Appendix}

Table 7 Bayesian information criterion (BIC) values

\begin{tabular}{|c|c|c|}
\hline Number of groups (all quadratic) & High N BIC & Low N BIC \\
\hline 2 & -15125.22 & -15114.34 \\
\hline 3 & -14727.17 & -14710.07 \\
\hline 4 & -14640.39 & -14607.07 \\
\hline 5 & -14386.73 & -14357.19 \\
\hline 6 & -14324.89 & -14289.13 \\
\hline 7 & -14297.76 & -14255.78 \\
\hline 8 & -14270.66 & -14222.47 \\
\hline 9 & -14246.76 & -14192.35 \\
\hline 10 & -14260.62 & -14199.99 \\
\hline \multicolumn{3}{|l|}{ Order of groups } \\
\hline 3333 & -14520.66 & -14491.12 \\
\hline 2222 & -14640.39 & -14607.07 \\
\hline 0222 & -14645.08 & -14624.87 \\
\hline 1222 & -14499.91 & -14478.14 \\
\hline 1122 & -14517.17 & -14496.96 \\
\hline 0122 & -14661.61 & -14642.96 \\
\hline 0333 & -14634.38 & -14609.51 \\
\hline 1333 & -14639.36 & -14612.93 \\
\hline 1322 & -14492.02 & -14468.70 \\
\hline 1332 & -14635.15 & -14610.28 \\
\hline
\end{tabular}

\section{References}

1. Altman, D. G., \& Bland, J. M. (2003). Statistics notes: interaction revisited: the difference between two estimates. British Medical Journal, 326, 219.

2. Ananth, C. V., Platt, R. W., \& Savitz, D. A. (2005). Regression models for clustered binary responses: implications of ignoring the intracluster correlation in an analysis of perinatal mortality in twin gestations. Annals of Epidemiology, 15(4), 293-301. doi:10.1016/j.annepidem.2004.08.007.

3. Andrews, D. A. (1995). The psychology of criminal conduct and effective treatment. In J. McGuire (Ed.), What works: reducing reoffending - guidelines from research and practice (pp. 35-62). New York: Wiley.

4. Andrews, D. A., \& Bonta, J. (2010). The psychology of criminal conduct. Cincinnati: Anderson.

5. Andrews, D. A., Zinger, I., Hoge, R. D., Bonta, J., Gendreau, P., \& Cullen, F. T. (1990). Does correctional treatment work? A clinically relevant and psychologically informed meta-analysis. Criminology, 28(3), 369-404. doi:10.1111/j.1745-9125.1990.tb01330.x.

6. Besemer, S. (2012). Intergenerational transmission of criminal and violent behaviour. Doctoral dissertation University of Cambridge. Leiden: Sidestone Press.

7. Besemer, S. (2014). The impact of timing and frequency of parental criminal behaviour and risk factors on offspring offending. Psychology, Crime \& Law, 20(1), 78-99. doi:10.1080/1068316X.2012.736512.

8. Besemer, S., \& Farrington, D. P. (2012). Intergenerational transmission of criminal behaviour: conviction trajectories of fathers and their children. European Journal of Criminology, 9(2), 120-141. doi:10.1177 $/ 1477370811422801$. 
9. Besemer, S., Farrington, D. P., \& Bijleveld, C. C. J. H. (2013). Official bias in intergenerational transmission of criminal behaviour. British Journal of Criminology, 53(3), 438-455. doi:10.1093 /bjc/azt006.

10. Bijleveld, C. C. J. H., \& Wijkman, M. (2009). Intergenerational continuity in convictions: a fivegeneration study. Criminal Behaviour and Mental Health, 19(2), 142-155. doi:10.1002/cbm.714.

11. Blumstein, A., \& Cohen, J. (1987). Characterizing criminal careers. Science, 237(4818), 985-991. doi:10.1126/science.237.4818.985.

12. Brottsbalken [The penal code] (1962:700). https://www.riksdagen.se/sv/DokumentLagar/Lagar/Svenskforfattningssamling/Brottsbalk-1962700_sfs-1962-700/ Accessed 10 December 2015 .

13. Bursik, R., Jr. (1980). The dynamics of specialization in juvenile offenses. Social Forces, 58, 851-864.

14. Bushway, S., Thornberry, T. P., \& Krohn, M. D. (2003). Desistance as a developmental process: a comparison of static and dynamic approaches. Journal of Quantitative Criminology, 19, 129-153.

15. Capaldi, D. M., DeGarmo, D., Patterson, G. R., \& Forgatch, M. (2002). Contextual risk across the early life span and association with antisocial behavior. In J. B. Reid, G. R. Patterson, J. J. Snyder, undefined author, \& undefined author (Eds.), Antisocial behavior in children and adolescents: A developmental analysis and model for intervention (pp. 123-145). Washington, DC: American Psychological Association.

16. Carlsson, C., \& Sarnecki, J. (2016). An introduction to life-course criminology. London: Sage.

17. Caspi, A., McClay, J., Moffitt, T. E., Mill, J., Martin, J., Craig, I. W., Taylor, A., \& Poulton, R. (2002). Role of genotype in the cycle of violence in maltreated children. Science, 297(5582), 851-854.

18. Eggleston, E., Laub, J., \& Sampson, R. (2004). Methodological sensitivities to latent class analysis of long-term criminal trajectories. Journal of Quantitative Criminology, 20(1), 1-26.

19. Erosheva, E. A., Matsueda, R. L., \& Telesca, D. (2014). Breaking bad: two decades of life-course data analysis in criminology, developmental psychology, and beyond. Annual Review of Statistics and Its Application, 1(1), 301-332. doi:10.1146/annurev-statistics-022513-115701.

20. Farrington, D. P. (2011). Families and crime. In J. Q. Wilson \& J. Petersilia (Eds.), Crime and public policy (pp. 130-157). New York: Oxford University press.

21. Farrington, D. P., Coid, J., \& Murray, J. (2009). Family factors in the intergenerational transmission of offending. Criminal Behaviour and Mental Health, 19(2), 109-124.

22. Farrington, D. P., Jolliffe, D., Loeber, R., Stouthamer-Loeber, M., \& Kalb, L. M. (2001). The concentration of offenders in families, and family criminality in the prediction of boys' delinquency. Journal of Adolescence, 24(5), 579-596. doi:10.1006/jado.2001.0424.

23. Farrington, D. P., \& Loeber, R. (1999). Transatlantic replicability of risk factors in the development of delinquency. In P. Cohen, C. Slomkowski, L. N. Robins, \& undefined author (Eds.), Historical and geographical influences on psychopathology. Mahwah, NJ: Lawrence Erlbaum.

24. Farrington, D. P., Barnes, G., \& Lambert, S. (1996). The concentration of offending in families. Legal and Criminological Psychology, 1, 47-63.

25. Field, A. (2005). Discovering statistics using SPSS (and sex, drugs and rock " $n$ " roll) (2nd ed.). London: Sage.

26. Fisher, G., \& Ross, S. (2006). Beggarman or thief: methodological issues in offender specialisation research. Australian \& New Zealand Journal of Criminology, 39(2), 151-170.

27. Forslund, I., von Hofer, H, \& Thorson , U. (2012): Kriminalitetsutveckling och -belastning belyst genom fördelsekohortstatistik.: Födda 1958-1991. [Crime development and criminal histories by bnirth statistics. Born 1958-1991] Stockholms Universitet, Kriminologiska Institutionen. Rapport 2012:3.

28. Friday, P. C. (1976). Sanctioning in Sweden: an overview. Federal Probation, 40, 48-55.

29. Gendreau, P. (1996). The principles of effective intervention with offenders. In A. T. Harland (Ed.), Choosing correctional options that work: defining the demand and evaluating the supply (pp. 117-130). Thousand Oaks: Sage.

30. Gendreau, P., Little, T., \& Goggin, C. (1996). A meta-analysis of the predictors of adult offender recidivism: what works! Criminology, 34(4), 575-608. doi:10.1111/j.1745-9125.1996.tb01220.x.

31. Gendreau, P., Smith, P., \& French, S. A. (2006). The theory of effective correctional intervention: empirical status and future directions. In F. T. Cullen, J. P. Wright, \& K. R. Blevins (Eds.), Taking stock: the status of criminological theory-advances in criminological theory (Vol. 15, pp. 419-446). New Brunswick: Transaction Publishers.

32. Giordano, P. C. (2010). Legacies of crime. A follow-up of the children of highly delinquent girls and boys. Cambridge: Cambridge University Press.

33. Goodman, L. (2007). On the assignment of individuals to latent classes. Sociological Methodology, 37, 1-22. 
34. Green, D. (2008). Suitable vehicles: framing blame and justice when children kill a child. Crime, Media, Culture, 4, 197-220.

35. Green, D. A. (2008b). When children kill children: political culture and penal populism, 328.

36. Haberman, S. J. (1973). The analysis of residuals in cross-classified tables. Biometrics, 29, 205-220.

37. Hanley, J. A., Negassa, A., Edwardes, M. D. D., \& Forrester, J. E. (2003). Statistical analysis of correlated data using generalized estimating equations: an orientation. American Journal of Epidemiology, 157(4), 364-375.

38. Hedderman, C., \& Gelsthorpe, L. (1997). Understanding the sentencing of women. Home Office Research Study 170. London: Home Office Research and Statistics Directorate.

39. Hjalmarsson, R., \& Lindquist, M. J. (2012). Like godfather, like son: exploring the intergenerational nature of crime. Journal of Human Resources, 47(2), 550-582.

40. von Hofer, H. (2003). Prison populations as political constructs: the case of Finland, Holland and Sweden. Journal of Scandinavian Studies in Criminology and Crime Prevention, 4(1), 21-38. doi:10.1080 /14043850310009921.

41. von Hofer, H. (2010). Sweden. In M. F. Aebi, V. Jaquier, \& G. R. Newman (Eds.), Crime and punishment around the world. Europe. Volume 4 (pp. 332-342). Santa Barbara, CA: ABC-Clio.

42. von Hofer, H. (2011). Brott och straff $i$ Sverige. Historisk kriminalstatistik 1750-2010. [Crime and punishment in Sweden]. diva-portal.org. Stockholm: Kriminologiska institutionen. Stockholms Universitet.

43. von Hofer, H., \& Lappi-Seppälä, T. (2014). The development of crime in light of Finnish and Swedish criminal justice statistics, circa 1750-2010. European Journal of Criminology, 11(2), 169-194. doi:10.1177/1477370813494976.

44. Janson, C.-G. (2004). Youth justice in Sweden. Crime and Justice, 31, 391-441. IS -.

45. Janson, C.-G., \& Wikström, P.-O. H. (1995). Growing up in a welfare state. In J. Hagan (Ed.), Delinquency and disrepute in the life course. Vol. 4 in Current perspectives on aging and the life cycle (pp. 191-215). Greenwich: JAI Press.

46. Jones, B. L., \& Nagin, D. S. (2007). Advances in group-based trajectory modeling and an SAS procedure for estimating them. Sociological Methods \& Research, 35(4), 542-571. doi:10.1177 /0049124106292364.

47. Jones, B. L., Nagin, D. S., \& Roeder, K. (2001). A SAS procedure based on mixture models for estimating developmental trajectories. Sociological Methods \& Research, 29(3), 374-393. doi:10.1177 /0049124101029003005.

48. Jonsson, G. (1967). Delinquent boys, their parents and grandparents. Acta Psychiatrica Scandinavica. Supplementum.

49. Jonsson, G. (1969). Det sociala arvet. [The social heritage]. Stockholm: Tiden.

50. Kendler, K. S., Ohlsson, H., Morris, N. A., Sundquist, J., \& Sundquist, K. (2014). A Swedish populationbased study of the mechanisms of parent-offspring transmission of criminal behavior. Psychological Medicine, 1-10. doi: 10.1017/S0033291714002268

51. Lag om särskilda bestämmelser av vård av unga [Act with Special Provisions for Care of the Young People] (1990: 52) http:/www.riksdagen.se/sv/Dokument-Lagar/Lagar/Svenskforfattningssamling/Lag199052-med-sarskilda-be_sfs-1990-52/ Accessed 10 December 2015.

52. Le Blanc, M., \& Loeber, R. (1998). Developmental criminology updated. Crime and Justice, 23, 115-198.

53. Lemert, E. M. (1967). Human deviance, social problems, and social control. Englewood Cliffs: Prentice Hall.

54. Liang, K., \& Zeger, S. (1993). Regression analysis for correlated data. Annual Review of Public Health, $14,43-68$.

55. Lipsitz, S. R., Laird, N. M., \& Harrington, D. P. (1991). Generalized estimating equations for correlated binary data: using the odds ratio as a measure of association. Biometrika, 78(1), 153-160.

56. Moffitt, T. E. (1993). Adolescence-limited and life-course-persistent antisocial behavior: a developmental taxonomy. Psychological Review, 100, 674-701.

57. Morris, N. (1966). Lessons from the adult correctional system of Sweden. Federal Probation, 30, 3-13.

58. Murray, J., Janson, C.-G., \& Farrington, D. P. (2007). Crime in adult offspring of prisoners: a crossnational comparison of two longitudinal samples. Criminal Justice and Behavior, 34(1), 133-149.

59. Nagin, D. S. (2004). A semi-parametric, group-based approach for analysing trajectories of development: a non-technical overview. In G. J. N. Bruinsma, H. Elffers, \& J. de Keijser (Eds.), Punishment, places and perpetrators: developments in criminology and criminal justice research (pp. 247-259). Collumpton: Willan Publishing. 
60. Nagin, D. S. (2004). Response to "methodological sensitivities to latent class analysis of long-term criminal trajectories.". Journal of Quantitative Criminology, 20(1), 27-35. doi:10.1023 /B:JOQC.0000016697.85827.22.

61. Nagin, D. S. (2005). Group based modeling of development. Cambridge: Harvard University Press.

62. Nagin, D. S. (2005). What has been learned from group-based trajectory modeling? Examples from physical aggression and other problem behaviors. The ANNALS of the American Academy of Political and Social Science, 602(1), 82-117. doi:10.1177/0002716205280565.

63. Nagin, D. S., \& Land, K. C. (1993). Age, criminal careers, and population heterogeneity: specification and estimation of a nonparametric, mixed poisson model. Criminology, 31(3), 327-362. doi:10.1111/j.1745-9125.1993.tb01133.x.

64. Piquero, A. R. (2008). Taking stock of developmental trajectories of criminal activity over the life course (pp. 23-78). New York: Springer New York. doi:10.1007/978-0-387-71165-2_2.

65. Piquero, A. R., Farrington, D. P., \& Blumstein, A. (2003). The criminal career paradigm. Crime and Justice, 30, 359-506.

66. Piquero, A. R., Farrington, D. P., \& Blumstein, A. (2007). Key issues in criminal career research. New analyses of the Cambridge Study in Delinquent Development. Cambridge: Cambridge University Press.

67. Pratt, J. (2008). Scandinavian exceptionalism in an era of penal excess: part I: the nature and roots of Scandinavian exceptionalism. British Journal of Criminology, 48(2), 119-137.

68. Robins, L. N. (1966). Deviant children grown up: a sociological and psychiatric study of sociopathic personality. Baltimore: Williams and Wilkins.

69. Robins, L. N. (1986). The consequences of antisocial behavior in girls. In D. Olweus, J. Block, \& M. Radke-Yarrow (Eds.), Development of antisocial and prosocial behavior: research, theories, and issues (pp. 385-414). Orlando: Academic Press.

70. Sarnecki, J. (1985). Predicting social maladjustment. Stockholm boys grown up I. Stockholm: Esselte Tryck.

71. Sarnecki, J. (2012). Den ökande sociala kontrollen och brottsutveckling. [The increased social control and crime development]. In L. Pettersson \& L. Pettersson (Eds.), Kontrollens variationer. [Variations of control] (pp. 321-349). Lund: Studentlitteratur.

72. Sherman, L. W. (1993). Defiance, deterrence, and irrelevance: a theory of the criminal sanction. Journal of Research in Crime and Delinquency, 30(4), 445-473.

73. Skardhamar, T. (2010). Distinguishing facts and artifacts in group-based modeling. Criminology, 48(1), 295-320. doi:10.1111/j.1745-9125.2010.00185.x.

74. Skardhamar, T. (2014). Criminal trajectories: taking stock and moving forward. The DLC Criminologist ASC Division of Developmental and Life Course Criminology, 2(1), 25-29.

75. Smith, P., Gendreau, P., \& Swartz, K. (2009). Validating the principles of effective intervention: a systematic review of the contributions of meta-analysis in the field of corrections. Victims \& Offenders, 4(2), 148-169. doi:10.1080/15564880802612581.

76. SOU 1971:49: 1956 års klientelundersökning rörande ungdomsbrottslingar. Unga lagöverträdare 1, Undersökningsmetodik. Brottsdebut och återfall. [1956 clientele study of juvenile offenders. Young offenders 1. Survey methodology. Crime onset and relapse.] Stockholm. Statens Offentliga Utredningar.

77. SOU 1995:91. Ett reformerat straffsystem: betänkande av Straffsystemkommittén. [A reformed penal system: report of the Penal System Committee.] Statens Offentliga Utredningar. Stockholm: Fritzes.

78. Thornberry, T. P. (2005). Explaining multiple patterns of offending across the life course and across generations. The Annals of the American Academy of Political and Social Science, 602 IS -, 156-195.

79. Thornberry, T. P. (2009). The apple doesn't fall far from the tree (or does it?): intergenerational patterns of antisocial behavior-the American Society of Criminology 2008 Sutherland address. Criminology, 47(2), 297-325.

80. Thornberry, T. P., \& Krohn, M. D. (2005). Applying interactional theory to the explanation of continuity and change in antisocial behavior. Integrated Developmental and Life-Course Theories of Offending. Vol 14. Ed David P. Farrington. London: Transaction, 183.

81. Thornberry, T. P., Freeman-Gallant, A., \& Lovegrove, P. J. (2009). Intergenerational linkages in antisocial behaviour. Criminal Behaviour and Mental Health.

82. van de Rakt, M. G. A. (2011). Two generations of crime: the intergenerational transmission of criminal convictions over the life course. Doctoral dissertation Radboud University Nijmegen, the Netherlands.

83. van de Rakt, M. G. A., Nieuwbeerta, P., \& Apel, R. (2009). Association of criminal convictions between family members: effects of siblings, fathers and mothers. Criminal Behaviour and Mental Health, 19(2), 94-108. doi:10.1002/cbm.715. 
84. van de Rakt, M. G. A., Nieuwbeerta, P., \& de Graaf, N. D. (2008). Like father, like son: the relationships between conviction trajectories of fathers and their sons and daughters. British Journal of Criminology, 48(4), 538-556. doi:10.1093/bjc/azn014.

85. van de Rakt, M. G. A., Ruiter, S., de Graaf, N. D., \& Nieuwbeerta, P. (2010). When does the apple fall from the tree? Static versus dynamic theories predicting intergenerational transmission of convictions. Journal of Quantitative Criminology, 26(3), 371-389. doi:10.1007/s10940-009-9089-3.

86. van de Weijer, S. G. M., Bijleveld, C. C. J. H., \& Blokland, A. A. J. (2011). De overdracht van gewelddadige delinquentie tussen drie generaties mannen. Tijdschrift Voor Criminologie, 53, 244-259.

87. van der Geest, V., Blokland, A. A. J., \& Bijleveld, C. C. J. H. (2009). Delinquent development in a sample of high-risk youth: shape, content, and predictors of delinquent trajectories from age 12 to 32 . Journal of Research in Crime and Delinquency, 46(2), 111-143. doi:10.1177/0022427808331115.

88. Ward, D. A. (1979). Sweden: the middle way to prison reform? In M. E. Wolfgang (Ed.), Prisons: present and possible (pp. 89-167). Lexington: Lexington Books.

89. Zeger, S., \& Liang, K. (1992). An overview of methods for the analysis of longitudinal data. Statistics in Medicine, 11, 1825-1839. 